\title{
Fatigue of Clip connectors for offshore drilling risers under biaxial tension
}

\author{
Vidit Gaur ${ }^{1,2}$, Armel-Brice Mbiakop-Ngassa ${ }^{1}$, Véronique Doquet ${ }^{1}$, Eléonore Roguet ${ }^{2}$ \\ and Emmanuel Persent ${ }^{2}$ \\ ${ }^{1}$ Laboratoire de Mécanique des Solides, CNRS, Ecole Polytechnique, France \\ ${ }^{2}$ IFPEN, Direction Mécanique Appliquée, Rueil-Malmaison, France
}

\begin{abstract}
Drilling riser connectors designed by IFPEN undergo cyclic in-phase biaxial tension in their critical area. This type of loading was reproduced on steel tubular specimens loaded in cyclic tension and internal pressure. The fatigue lives were substantially reduced when the load biaxiality was increased from 0 to 0.4 and then further to 1 , which was not captured by existing fatigue criteria. A deeper investigation is thus in progress. Emphasis is laid on the separate evaluation of mean stress and biaxiality effects, often treated in the same way in existing criteria. The influence of load biaxiality on the resistance of the steel to fatigue-corrosion in seawater will also be investigated.
\end{abstract}

\section{Introduction}

In order to increase the oil production from sub-oceanic reserves, efforts have to be made for deeper offshore drilling through riser steel tubes. The design of offshore structures has to integrate a reliable assessment of their durability under complex cyclic loadings in a corrosive environment (sea water and in some cases, $\mathrm{H}_{2} \mathrm{~S}$-containing products). IFPEN designed a Clip connector to join easily the riser tubes. Finite elements computations show that this component undergoes cyclic in phase biaxial tension with an $\mathrm{R}$ ratio close to zero in its critical area, while most of the multiaxial fatigue criteria in the literature were formulated and identified using fatigue data from combined tension and torsion tests. Fatigue crack growth in a biaxial tension field has been investigated by several teams who generally concluded that the secondary, non singular tensile stress slightly reduces the crack growth rate. This effect probably explains why in low cycle fatigue, biaxial tension may have a beneficial effect on fatigue lives [1]. By contrast, few experimental studies were devoted to fatigue crack initiation under biaxial tension [1-5] and several show that existing fatigue criteria do not represent well these data. In addition, an increase in stress triaxiality might enhance the detrimental effect of a corrosive environment on the component durability. All these elements led IFPEN and LMS to launch an experimental study of fatigue and corrosion-fatigue of F22 steel in biaxial tension, based on combined tension and internal pressure cyclic tests on tubular specimens.

This is an Open Access article distributed under the terms of the Creative Commons Attribution License 4.0, which permits unrestricted use, distribution, and reproduction in any medium, provided the original work is properly cited. 

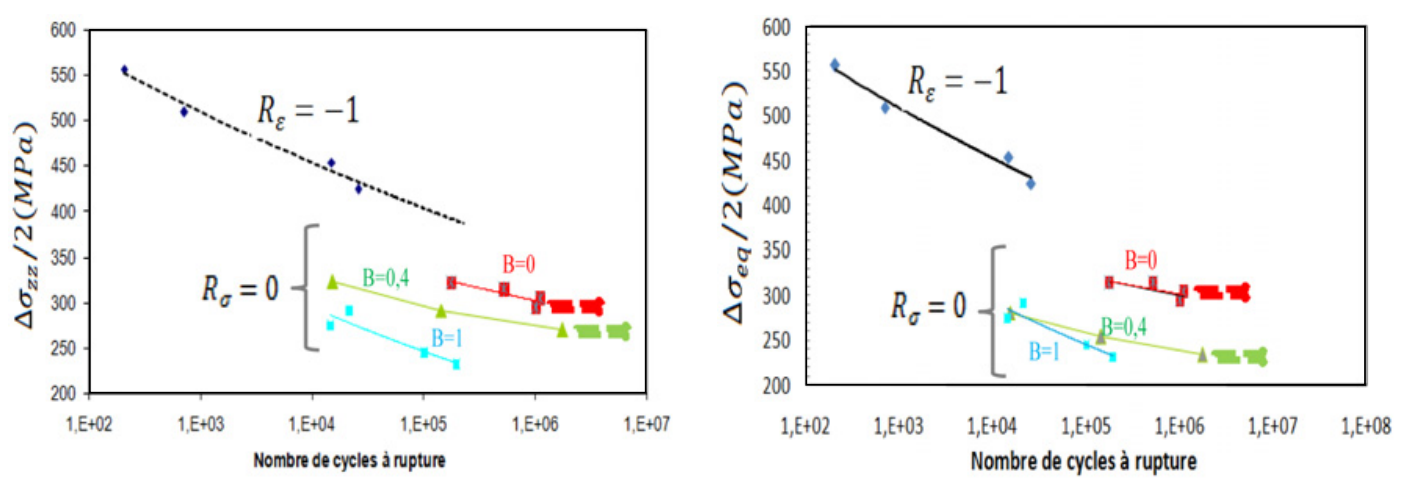

Figure 1. Lack of correlation of fatigue lives in cyclic, in phase tension and pressure with a) $\Delta \sigma_{\mathrm{zz}}$ and b) $\Delta \sigma_{\text {eqMises }}$.

\section{Experimental procedures}

The Clip connectors are constituted with F22 steel (containing 2 to $2.5 \mathrm{w} \% \mathrm{Cr}, 0.87$ to $1.13 \mathrm{w} \% \mathrm{Mo}, 0.3$ to $0.6 \mathrm{w} \% \mathrm{Mn}$ and 0.05 to $0.15 \mathrm{w} \% \mathrm{C}$ ). The material exhibits an aged martensitic microstructure with $7 \mu \mathrm{m}-$ wide equiaxial grains, themselves containing more or less lamellar features, with no significant texture. Cylindrical specimens $8 \mathrm{~mm}$ in diameter, as well as tubular specimens with an internal diameter of $23 \mathrm{~mm}$, a wall thickness of $1 \mathrm{~mm}$ and a gage length of $16 \mathrm{~mm}$ were cut along the longitudinal direction of a Clip connector. The cylindrical specimens were used for uniaxial fatigue tests. Strain-controlled LCF tests, all run at a strain rate of $10^{-3} \mathrm{~s}^{-1}$ were used to identify elastic-plastic constitutive equations and stress-controlled $\mathrm{HCF}$ tests run at $10 \mathrm{~Hz}$ at three different $\mathrm{R}$ ratios $(0,-0.5,-1)$ to investigate mean stress effects. Stress-controlled in-phase tension and internal pressure tests were run at $10 \mathrm{~Hz}$ in air on tubular specimens equipped with a biaxial extensometer measuring both the axial and diametral strains, using a triaxial testing machine $( \pm 100 \mathrm{KN}, \pm 600 \mathrm{Nm}, 1400$ bars $)$. Similar tests at a lower frequency will be run in synthetic sea water to investigate the influence of biaxiality on corrosion-induced life debit.

\section{Results}

As shown on Fig. 1, the fatigue life is substantially reduced when the load biaxiality (B) changes from 0 to 0.4 and to a lesser extent when it further increases to 1 . This effect is visible when the fatigue lives are plotted versus the axial stress range (Fig. 1a) or versus Von Mises equivalent stress range (Fig. 1b). Attempts to fit these data using several fatigue criteria from the literature (Smith-WatsonTopper, Dang-Van, Sines, Crossland) produce poor results. Fractographic observations suggest more frequent cleavage of ferrite around the crack initiation site under biaxial tension, which might be a reason for the detrimental effect of biaxial loading. A deeper investigation is in progress.

\section{References}

[1] V. Doquet, V. De Greef. Int. J. Fatigue 23, 135-145 (2001)

[2] H. Dietmann,T. Bhonghibhat, A. Schmid, proc. 3rd ICBMF, Stuttgart 2. paper 61 (1989)

[3] D. Lefebvre, H. Mebrouk, A. Makinde, proc. 3rd ICBMF, Stuttgart 2. paper 60 (1989)

[4] V. Bonnand, J.L. Chaboche, P. Gomez, P. Kanouté, D. Pacou, Int. J. Fatigue 33 1006-1016 (2011)

[5] I. Koutiri, D. Bellett,F. Morel, L. Augustins,J. Adrien, Int. J. Fatigue 47 44-57 (2013) 